\title{
Leaping the language gap: strategies for preschool and head start teachers
}

\author{
Carolyn Davidson Abel ${ }^{1 *}$, Jannah Walters Nerren ${ }^{2}$ and Hope Elizabeth Wilson ${ }^{3}$
}

\author{
* Correspondence: cabel@sfasu.edu \\ 'Department of Elementary \\ Education, Early Childhood Research \\ Center, Stephen F. Austin State \\ University, Station: 2428 Raguet \\ Street, Box 13017-SFA, Nacogdoches, \\ TX 75962, USA \\ Full list of author information is \\ available at the end of the article
}

\begin{abstract}
Strategies that promote the development of language skills are recognized as important in early childhood education. For early childhood centers and care providers, there are also additional concerns that interventions which meet these developmental needs are both time and cost effective. This pilot study investigates the effect of indirect language stimulation (ILS) techniques on the receptive and expressive oral language of 4-year-olds, using techniques that can be easily taught to teachers and implemented in the classroom. Two preschool teachers in a southwest rural community in the United States were randomly assigned for instruction over a 6-month period on effective ways of integrating ILS techniques into their regular classroom instruction. Students were assessed with the PPVT-4 (receptive language) and the EVT-2 (expressive language) to determine the effect these techniques had on their English language vocabulary. Results indicate that students in classrooms where teachers received the professional development $(n=31)$ had significantly higher growth in expressive language scores $(p=.012)$ than students in comparison classrooms $(n=34)$. This study suggests that a low-cost 2-day training intervention can be beneficial for preschool teachers and their 4-year-old students' language acquisition.
\end{abstract}

Keywords: Head Start; Preschool; Receptive; Expressive language; Professional development

\section{Background}

English language development at the preschool level has been linked with early academic success (National Reading Panel 2000; Peterson et al. 2010; Whitted 2010). Children in the United States from backgrounds of poverty and those whose first language is not English often exhibit less well developed language skills and face greater risks to academic success than do their more privileged classmates (e.g., Fry and Gonzales 2008; Lopez and Velasco 2011; Hart and Risley 2003; Pikulski and Tobin 1989; Rafferty and Griffin 2010). The disadvantages attributed to a lagging language development increase as children progress through school (e.g., Cuthrell et al. 2010; Hurley and Villamil 2001; Schmid and Kopke 2007; Westby and Hwa-Froelich 2010). Early interventions that support the development of language skills in young children have been shown to promote academic success at the preschool level (Cuthrell et al. 2010) and appear to have positive and substantial long-term effects. This can be seen across North America, Europe, and Asia (Burger 2010), indicating cross-cultural results, as well.

\section{Springer}


The current study was conducted in two Head Start classrooms at one childcare center in rural east Texas. Head Start is a federally funded program in the United States designed to promote school readiness for preschoolers from low-income families where the need to address inequalities and gaps in early learning persist (NAEYC Position Statement 2009). This study tested the efficacy of a particular early intervention technique derived from an indirect language stimulation (ILS) approach to language acquisition for culturally and linguistically diverse (CLD) children who are most at risk. A particular benefit of the treatment utilized in this study is the low cost and ease with which the language techniques appear to be learned and implemented by teachers during normal Head Start classroom hours.

\section{Theoretical framework}

There is not one way or single term to describe how children learn language best, but the research shows that a hybrid of techniques in responsive stimulating environments that engage children and respond to their interests seem to be effective (Hoff 2001; Warren and Yoder 1994). Under this interactionist view of language learning, language is constructed by the child through interactions with others, particularly adults (Hoff 2001). Vygotsky (1933) stresses the importance of social interactions with competent language users that are within the child's zone of proximal development (ZPD). McLeod (2007) refers to this space as the 'difference between what a child can achieve independently and what a child can achieve with guidance and encouragement from a skilled partner' (p. 6). Within this zone of instruction and learning, rich verbal interactions accompanied by reinforcing environmental cues are known to improve language development (Pence and Justice 2008; Bouchard et al. 2010). Such approaches, often termed 'indirect language stimulation' (ILS), have been shown to be effective in toddlers (e.g., Tabors 1998), children with developmental delays (Cornerstones 2009; Peterson et al. 2010), and children from backgrounds that place them at risk for language delays (Diaz-Rico 2013; Levine and McCloskey 2013). Additionally, children who are exposed to an environment rich in vocabulary and supportive of verbal interaction with adults develop a greater facility with language than those not afforded such opportunities (Owens 2008a; Dickinson, 2001). In brief, children who are behind their preschool peers in language proficiency benefit greatly from rich verbal interaction with adults as they need more (vocabulary instruction); they need it sooner; and they need it with more intentional supports and scaffolds' (Taffe 2009, p. 321) than is required by their peers. When early interventions of this sort focus on matching adult language to the child's current focus of attention which makes the experienced more personalized, there are significant long-term positive effects on the academic success of young children (Cornerstones 2009).

In the ILS framework, the manner in which adults interact verbally with children and the social context in which children's language interaction is stimulated are key. Low-anxiety social settings that afford opportunities for purposeful verbalizations and build upon the interests of the child facilitate language skill development most effectively, and this includes second language learners (Lessow-Hurley 2003). In addition, when adults properly extend or restate what children say, model and distinctly enunciate quality language, and intentionally make time to talk with children, the process 
of language acquisition is accelerated (Cornerstones 2009; Pence and Justice 2008). These interactions are most effective when they are directed toward the child's current focus or interest (stimulus) and current level of language development with appropriate scaffolding in a risk-free informal setting (Owens 2008b). In brief, for young language learners, it is preferable for teachers to more closely follow the child's lead, limiting extensions of the child's language by using indirect and less complex language stimulation techniques more closely matched to the child's early language level (Tsybina et al. 2006).

Early childhood educators are clearly adults who play a critical role in early language development. As teachers learn about how language develops in young children, they can become more equipped to facilitate its development (Tinajero et al. 1998). Thus, the present study focused upon training teachers to use some of these indirect language stimulation (ILS) techniques to test whether the vocabulary of children might be improved.

Based upon the research indicating the importance of language development (e.g., Peterson et al. 2010), particularly for students from poverty (e.g., Fry and Gonzales 2008), this current study was designed to test the effectiveness of time and cost-effective strategies for English language development for children in Head Start programs. Using a Vygotzkian approach based on social interactions and language developments, ILS techniques were studied. These built upon the language already utilized by the children through carefully designed interactions with the teachers. The researchers have hypothesized that these strategies would be effective in increasing the language development of children with backgrounds of poverty, providing cost- and time-effective interventions for early language.

\section{Methods}

The current study investigates the effect of professional development in indirect language stimulation (ILS) techniques for two randomly assigned Head Start teachers at one early childhood center on the expressive and receptive oral English language development of the 4-year-old children in their classrooms. Head Start is a federally funded program in the United States that promotes school readiness for preschoolers from low-income families. The Head Start program utilized for this study was selected because it represented a population of interest (i.e., children from backgrounds of poverty with diverse ethnicity and language) and mutual cooperation between the researchers and center administration.

\section{Participants}

The sample utilized for this study consisted of four teachers and 74 children in four preschool classrooms in a Head Start program at an early childhood center in rural southwest United States. The center was selected for its proximity to the researchers. Within the center, half of the classroom teachers were randomly assigned to participate in the professional development, and the children in those classrooms comprised the intervention group. The remaining two classrooms at the center comprised the comparison group of two teachers who did not receive the professional development but were promised the opportunity to learn the techniques the following year. All teachers in the study had at least 3 years of teaching experience in the preschool setting 
and none spoke Spanish, although there was a Spanish-speaking paraprofessional in each classroom to assist with instruction for the Spanish-speaking children with limited English proficiency. Dr. Michael E. Walker, Chair of the Stephen F. Austin State University Institutional Review Board for the Protection of Human Subjects in Research.

The demographic characteristics of the student sample resemble the demographics of the population of the county in terms of first and second language users (U.S. Census Bureau 2010). See Table 1 for demographic information for the 74 participants in the study. All of the Head Start students were considered economically disadvantaged as defined by federal guidelines (annual income of less than $\$ 22,050$ for a family of four). Over a third of the children came from Spanish-only-speaking homes $(n=25)$. Approximately equal numbers of students participated in the intervention group $(n=36)$ as the comparison group $(n=38)$. The comparison group was comprised of $37 \%$ Spanish-speaking children, whereas the intervention group had $31 \%$. This is representative of a national trend in the U.S. which indicates that English language learners in Head Start and Early Head Start (younger than 3 years of age) programs tend to be around 30\% and rising (National Clearinghouse for English Language Acquisition and Language Instruction Educational Programs NCELA 2011).

\section{Instrumentation}

The PPVT-4, measuring receptive oral English language development, was selected for its recognition and popularity in the field, the focus on early oral language, ability to inform instructional decisions for children learning English, and the easy early level high frequency words particularly designed for English language learners. As a nationally normed assessment, the reliability of scores $(\alpha=.97)$ and validity of the test as compared to other measures remains quite high (Dunn and Dunn 2007).

The EVT-2, measuring expressive English language development, was selected for its validity and reliability as a measure of the development of expressive oral language and appeal to young children, as well. As a nationally normed assessment, the reliability of

Table 1 Descriptive statistics of 4-year-old sample from low SES

\begin{tabular}{ccc}
\hline & $\boldsymbol{n}$ & Percentage \\
\hline Pre-test & 74 & .49 \\
Intervention & 36 & .14 \\
Spanish speaking & 11 & .32 \\
English speaking & 25 & .51 \\
Control & 38 & .18 \\
Spanish speaking & 14 & .32 \\
English speaking & 24 & \\
Post-test & 67 & .48 \\
Intervention & 32 & .15 \\
Spanish speaking & 10 & .33 \\
English speaking & 22 & .52 \\
Control & 35 & .22 \\
Spanish speaking & 15 & .30 \\
English speaking & 20 & \\
\hline
\end{tabular}


scores $(\alpha=.94)$ and validity of this test as compared to other measures is also quite high (Williams 2007).

\section{Intervention}

The theoretical framework and research concerning socially constructed language informed our decision to investigate the effectiveness of professional development for early childhood educators using ILS techniques. Specifically, the intervention consisted of a video training program entitled Good Talking with You (Educational Productions, 1987). These videos demonstrate how to stimulate the use of language development in normally developing and language-delayed preschool children by employing ILS techniques that are considered developmentally appropriate for young children (Bohannon and Bonvillian 1997; Bredekamp, 2011; National Reading Panel 2000; Pence and Justice, 2008). Accordingly, it was anticipated in the present study that these simple language techniques would support both children learning English and children from backgrounds of poverty as their English skills developed (Tabors 1998).

Advantages to employing this particular film included its clarity and appealing presentation of the intervention techniques, the ease of integrating ILS techniques into the day-to-day interactions of any school routine, and its flexibility in adapting to individual language levels and interests of all children. Additionally, training employing the film involved minimal expense, making it appealing for programs with budgetary constraints. The videos were supplemented with role-playing and hands-on activities conducted on the second day of the 2-day training workshop. All participants were given time to interact with children in the training setting in order to practice the techniques before attempting them in their own classrooms.

Specific skills taught during the professional development training began with the first level of parallel talk that encourages early attempts from children by improving their receptive language using the technique of 'saying what the child sees.' For instance, the teacher will sit next to the child and talk about what the child is doing or seeing. An example of this might occur during lunch where a non-verbal child is seen eating an apple. The teacher simply comments, 'You are eating an apple.' The child's attention is directed at the apple; the teacher merely labels it and later seeks opportunities to repeat the new word, based on the child's focus and interest. More advanced levels draw the child into conversation by using and extending the child's words, modeling and encouraging conversation with other children at the level of language they are using, and supporting all attempts to communicate in a non-threatening manner. Examples include responding to a child's comment, 'I maked a twuck', with 'Yes, you made a truck.' Emphasis is placed on following the child's lead, enunciating distinctly, and reducing the complexity of response when dialoguing with the children, especially those functioning at lower language levels.

Based upon the increased importance of early language development in the research, this study was conducted to preliminarily test the effectiveness of ILS techniques in early childhood. This intervention is designed to be easily implemented in early childhood settings in a cost-effective manner (e.g., it does not require the purchase of special materials or extended professional development). 


\section{Program fidelity}

Prior to beginning and following the completion of the 2-day professional development, participating teachers were given a short assessment of their knowledge of the language stimulation techniques (Appendix A). The instrument totaled 20 questions with five addressing each of four distinct levels of language development targeted by the treatment strategies (children speaking no words, few words, phrases, or sentences). These assessments were developed by the researchers with input from experts in the field and designed to match the four teaching videos in the treatment which described and provided examples of each of the four levels. These assessments were intended to provide some idea of the treatment understanding of these strategies before and after the professional development training. Discussion followed the post testing to further clarify any misunderstanding of language strategies in the treatment group.

During the classroom implementation phase after the professional development, the intervention teachers integrated the indirect language stimulation techniques into their regular classroom instruction. This center utilized a developmentally appropriate hands-on learning environment, with children actively participating in learning center activities and engaging in both small and whole group lessons with the classroom teacher. The interactive classrooms allowed the children to work independently, both with adults in the classroom and with their peers. The language stimulation techniques were incorporated into this environment, with the implementation teachers interacting with their preschool learners during daily routines and activities, including mealtimes and indoor and outdoor play. Comparison classroom teachers continued to teach according to their normal classroom practice.

Program fidelity was monitored with monthly 30-min observations using a researcher-designed and field-tested teacher observation form (see Appendix B). The facilitator/researcher made the visits since it was felt that the positive informal rapport established during professional development training ensured these visits would seem less threatening to intervention teachers. One observer was used throughout the study to maintain consistency of implementation of the rubric and results, as well as to minimize disruption to the classroom procedures.

Intervention teachers were rated on a scale of 0 (no use of strategies) to 5 (excellent use of strategies). Observations in treatment classrooms revealed the intervention teachers averaged a 3 to 4 (average to good) level of implementation of language stimulation techniques on the scale of 0 to 5 (5 indicating an excellent level of quality language support, 4 indicating good interaction with few missed opportunities, and 3 showing average engagement with children with some missed opportunities). This helped confirm that the intervention teachers understood and were implementing the new language stimulation techniques with their students.

\section{Data collection}

In order to measure the growth in receptive and expressive language, a trained and experienced tester administered the oral receptive Peabody Picture Vocabulary Test (PPVT-4) and the Expressive Vocabulary Test (EVT-2) to the children in the treatment and control classrooms late in September, prior to the beginning of the study, and again 
in early April, 6 months following the professional development. This allowed the researchers to investigate the effect of the intervention on both receptive and expressive vocabulary of the participants.

\section{Data analyses}

Results of the measures of receptive and expressive vocabulary were analyzed using an analysis of covariance (ANCOVA), determining the differences between intervention and comparison groups on the posttest scores, while controlling for pretest scores and home language. An ANCOVA was used to analyze the results, because it allows for the consideration of the home language of the child (Spanish or English) and the intervention group, as well as the interaction between these variables in simultaneous analyses. Although the sample size was small for this pilot study, it is known that primary language is an important factor in the development of English language skills (e.g., Goodrich et al. 2014). The authors acknowledge that this does ignore the nested nature of the data (e.g., that the children were also grouped into classrooms for instruction); this is a pilot study of the intervention, and there was no sufficient power to analyze the results in a hierarchical model.

\section{Results}

\section{Program fidelity findings}

Pretest scores of the intervention teachers had a mean level of $45.0 \%$ understanding $(\mathrm{SD}=14.14)$ of language stimulation techniques before the training began. Posttest scores revealed a mean of $77.5 \%$ ( $\mathrm{SD}=3.54$ ), indicating participants had improved an average of $32.5 \%(\mathrm{SD}=10.67)$ in their knowledge of the strategies over the course of a 2-day professional development; due to the low sample size, however, this is not statistically significant $(t[1]=-7.00)$. Thus, these data are presented as descriptive of the intervention, rather than to make generalizations about a larger population, as in inferential statistics. Discussions with intervention teachers about the test answers revealed a tendency with this group to favor more complex language responses, much like the concern noted in the recast studies (Nelson et al. 1996).

The analysis of the 30-min, monthly classroom observations measuring the fidelity to the intervention revealed that teachers were regularly implementing the techniques with good success, earning scores averaging 3 (average use) to 4 (good use of strategies) at each observation.

\section{Program effects}

The pretest scores of the children on the PPVT-4 showed a low mean standard score $(M=77.7, \mathrm{SD}=16.1)$, with a large increase in English vocabulary over 6 months for both treatment and control groups $(M=90.4, \mathrm{SD}=13.3)$. As would be expected, the Spanish-speaking children showed the lowest (English) pretest scores $(M=63.7$, $\mathrm{SD}=16.8$, treatment group; $M=62.9, \mathrm{SD}=16.4$, control group) as compared to the native English-speaking students $(M=86.4, \mathrm{SD}=17.0$, treatment group; $M=82.9$, $\mathrm{SD}=10.6$, control group). See Table 2 for results.

Similar results were seen for the tests of expressive language on the EVT-2, with a low mean standard score in the pretest results $(M=78.8, \mathrm{SD}=19.5)$ and a large increase over 
Table 2 Descriptive statistics of the receptive English language, PPVT-IV

\begin{tabular}{clll}
\hline & $\boldsymbol{n}$ & Mean & SD \\
\hline Pre-test & 74 & 77.7 & 16.1 \\
Intervention & 36 & 79.8 & 18.8 \\
Spanish speaking & 11 & 63.7 & 16.8 \\
English speaking & 25 & 86.4 & 17.0 \\
Control & 38 & 75.7 & 15.5 \\
Spanish speaking & 14 & 62.9 & 16.4 \\
$\quad$ English speaking & 24 & 82.9 & 10.6 \\
Post-test & 67 & 90.4 & 13.3 \\
Intervention & 32 & 91.1 & 13.4 \\
Spanish speaking & 10 & 82.9 & 10.3 \\
English speaking & 22 & 94.9 & 13.2 \\
Control & 35 & 89.7 & 13.3 \\
Spanish speaking & 15 & 80.5 & 10.3 \\
English speaking & 20 & 96.7 & 11.0 \\
\hline
\end{tabular}

6 months for both treatment and control groups $(M=85.6, \mathrm{SD}=15.0)$. Again, the Spanish-speaking students had lower pretest scores $(M=63.6, \mathrm{SD}=16.7$, treatment group; $M=62.9, \mathrm{SD}=16.4$, control group) as compared to the English-speaking students ( $M=83.8, \mathrm{SD}=20.0$, treatment group; $M=89.4, \mathrm{SD}=12.3$, control group). See Table 3.

A two-by-two between-groups analysis of covariance was conducted to assess the effectiveness of the language intervention on receptive vocabulary for the sample. The independent variables were participation in the intervention and language spoken at home (English or Spanish). The dependent variable was the score on the PPVT-4 administered after the intervention program. Scores on the PPVT-4 prior to the commencement of the intervention were used as a covariate to control for individual differences.

Table 3 Descriptive statistics of the expressive English language, EVT-2

\begin{tabular}{clll}
\hline & $\boldsymbol{n}$ & Mean & SD \\
\hline Pre-test & 74 & 78.8 & 19.5 \\
Intervention & 36 & 77.9 & 20.8 \\
Spanish speaking & 11 & 63.6 & 16.7 \\
English speaking & 25 & 83.8 & 20.0 \\
Control & 38 & 79.6 & 18.9 \\
Spanish speaking & 14 & 62.9 & 16.4 \\
English speaking & 24 & 89.4 & 12.3 \\
Post-test & 65 & 85.6 & 15.0 \\
Intervention & 31 & 88.6 & 15.0 \\
Spanish speaking & 10 & 77.4 & 15.8 \\
English speaking & 21 & 93.9 & 11.5 \\
Control & 34 & 82.8 & 14.6 \\
Spanish speaking & 14 & 69.6 & 9.4 \\
English speaking & 20 & 92.1 & 9.6 \\
\hline
\end{tabular}


Table 4 ANCOVA of PPVT

\begin{tabular}{lllllll}
\hline Source & Sum of squares & df & Mean squares & $\boldsymbol{F}$ & $\boldsymbol{p}$ & Partial eta squared \\
\hline PPVT pretest scores & $4,872.23$ & 1 & $4,872.23$ & 85.10 & $<.001$ & .579 \\
Intervention & 1.08 & 1 & 1.08 & .02 & .891 & $<.001$ \\
Language & 5.19 & 1 & 5.19 & .09 & .764 & .001 \\
Intervention $\times$ language & 114.19 & 1 & 114.19 & 1.99 & .163 & .031 \\
Error & $3,549.55$ & 62 & 57.25 & & & \\
Total & $559,235.00$ & 67 & & & & \\
\hline
\end{tabular}

Note: $R^{2}=.696$.

After adjusting for PPVT-4 scores prior to the beginning of the intervention, the ANCOVA demonstrated that there was no significant interaction between students receiving the intervention and their home language $(F[1,62]=1.99, p=.163)$. Neither of the main effects were statistically significant (intervention, $F[1,62]=.02, p=.891$; language, $F[1,62]=.09, p=.764$ ). See Table 4 for results of this analysis. These results suggest that the intervention did not have an effect on the receptive language of either students from English-speaking or Spanish-speaking homes.

Another analysis of covariance was conducted to assess the effectiveness of the language intervention on expressive vocabulary for the sample. The independent variables remained the same as in the previous analysis. The dependent variable was the score on the EVT-2 administered after the intervention program. After adjusting for EVT-2 scores prior to beginning the intervention, there was no significant interaction between receiving the intervention and home language $(F[1,60]=.09, p=.772)$. See Figure 1 for an illustration of these effects and Table 5 for the results of this analysis. However, both the intervention and the home language represent a small effect size (language partial eta squared $=.141$; intervention partial eta squared $=.100$ ). In conclusion, after controlling for pre-test scores, students in Head Start classrooms in which the teacher received the language training $(n=31)$ had statistically significantly higher expressive English language scores $(p=.012)$ than students in Head Start classrooms with teachers who had not received the language training $(n=34)$.

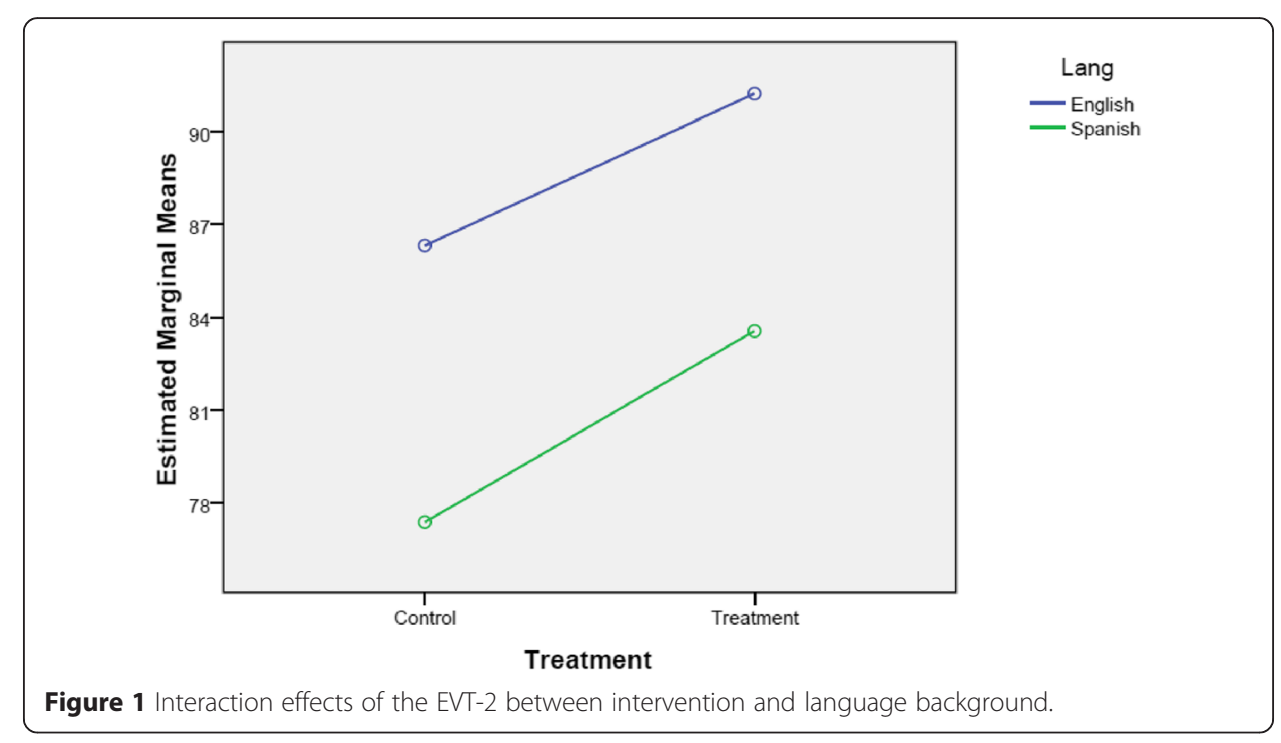


Table 5 ANCOVA of EVT

\begin{tabular}{lllllll}
\hline Source & Sum of squares & df & Mean squares & $\boldsymbol{F}$ & $\boldsymbol{p}$ & Partial eta squared \\
\hline EVT pretest scores & $3,642.06$ & 1 & $3,642.06$ & 53.01 & $<.001$ & .469 \\
Intervention & 456.41 & 1 & 456.41 & 6.64 & .012 & .100 \\
Language & 677.41 & 1 & 677.41 & 9.86 & .003 & .141 \\
Intervention $\times$ Language & 5.82 & 1 & 5.82 & .09 & .772 & .001 \\
Error & $4,122.14$ & 60 & 68.70 & & & \\
Total & $490,075.00$ & 65 & & & & \\
\hline
\end{tabular}

Note: $R^{2}=.712$

\section{Discussion}

Overall, the pre-test results indicate that the children from backgrounds of poverty at the Head Start centers in this study had low language skills, as compared to the norming population of the standardized measures. This is consistent with previous studies (e.g., Hart and Risely 2003). In addition, although the effect was small, the results indicate that children in classes in which the teachers had attended the 2-day professional development on early language interventions had significantly higher expressive vocabulary scores, as compared with the control group of children with teachers who did not attend the professional development. On the other hand, there were no significant differences in the receptive language scores between the two groups. There are three important discussions from these results: a need for early childhood language interventions for children from poverty; implications for advances in receptive language; and implications for advances in expressive language.

\section{Need for intervention}

The first finding of this study underscores the importance of early language interventions for children from backgrounds of poverty with diverse language backgrounds. The children in this study, whose families met the federal guidelines as economically disadvantaged, scored well below the mean for the norming sample in both expressive and receptive language at the pretest. Specifically, in receptive English language, the entire sample scores $(M=77.7)$ put the children in the sixth percentile as compared to the norming sample (Dunn and Dunn 2007) and the Spanish-speaking subgroup $(M=63.7)$ in the first percentile (Dunn and Dunn 2007). For expressive English vocabulary, the entire sample mean score $(M=78.8)$ was in the seventh percentile (Williams 2007), and the Spanish-speaking subgroup $(M=63.6)$ was in the lowest first percentile (Williams 2007). As compared to typically developing children, the Head Start children in this study began with substantially lower scores. This emphasizes the need for language interventions among this population of students, which include children both from backgrounds of poverty and those with diverse language backgrounds, particularly interventions that provide time- and cost-effective support for teachers. This finding is common among studies of children from backgrounds of poverty and supported by other research (e.g., Fernald et al. 2013; Law et al. 2011; Lonigan et al. 2013). It appears that teacher professional development, such as was highlighted in this study, can provide cost-effective and feasible interventions for this population. 


\section{Receptive language}

There was not a statistically significant effect demonstrated of the intervention on the receptive language of 4-year-old children in this study. Several factors may explain this result. First, the sample size of the study is fairly small and may not have enough power to detect differences if the effect of the intervention is small to moderate. However, since the effect size of the intervention is also small $(<.001)$, it is more likely that the intervention did not affect the growth in receptive language of the children during the duration of the study. This may be due to the age and language skills of the children. It is possible that benefits of the program on receptive language might be seen in younger children, as receptive language typically develops prior to expressive language. At 4 years of age, the children's receptive language may have a slower rate of increase, because the initial dramatic increases in receptive language in English have already been experienced as seen in other studies investigating acquisition of language (e.g., Glennen et al. 2014). Thus, the time frame of the study may not have been long enough to document this growth over time. In addition, the intervention is focused primarily on developing expressive language of children, with less emphasis on comprehension of vocabulary. Therefore, changes in receptive language may not be expected from this intervention.

There may be other reasons to explain this limited result. Given receptive language is more advanced than expressive, the receptive level of these students may have moved beyond (less influenced by) the ILS strategies which tend to emphasize comprehensible input during interactions with adults and later interactions with peers which are not completely spontaneous - something considered by Jarvis and Krashen (2014) in their study of electronic influences on early- and late-level language acquirers. It is possible that the receptive level of these students is becoming advanced enough to benefit more from self-directed social interaction typical of children this age who have acquired language competence sufficient to engage with peers in personalized conversations which will enable them to use their language with increasing skill (Jarvis and Krashen 2014); this is consistent with current language development theory that appears to reflect the importance of developing automaticity with all skills we learn-'the solution (lies) not in expensive equipment, exotic methods, sophisticated linguistic analyses, or new laboratories, but in full utilization of what we already have (using the new skill for authentic purposes). The best methods might (just) be the most pleasant' (Krashen 1982, p. 1). Last, given the points above, the ILS techniques may offer comprehensive input at the lower levels that provide easy access and incentive for students to learn English after which fluency building using the new language would naturally follow - thus, these strategies for building expressive skills would then be seen as providing a 'jump start' for language development to blossom.

\section{Expressive language}

Both intervention and comparison groups made substantial gains in expressive language over the 6 months of the study. In addition, the intervention had a statistically significant effect on the expressive English language of the children in treatment classrooms when compared with the group of children not with teachers who participated in the professional development. This indicates that the language stimulation techniques 
were effective at addressing some of the gaps in language development of these children. However, the effect size of this intervention was small. As this intervention consisted of a 2-day professional development opportunity paired with relatively short follow-up, this intervention could be a cost-effective and easily implemented program for a variety of early childhood settings, including childcare centers. Other research should investigate such interventions further; perhaps longer and more intense interventions would yield larger growth.

In looking at home language background, the native English-speaking students had higher scores overall, as might be expected from an assessment of English language in the United States. However, the interaction between home language and intervention was not significant, indicating that the strategies were equally as effective for both groups. Overall, we can conclude that by providing direct instruction to teachers regarding language stimulation techniques, the program shows preliminary results indicating favorable outcomes for the expressive language of children, as has been found in other studies using more intensive curriculum interventions (e.g., Justice et al. 2008).

\section{Limitations}

As with the studies of children from backgrounds of poverty explored by the National Early Literacy Panel (NELP 2008), one limitation of this research is the small sample size. With a larger group, it would be possible to analyze the results for specific subpopulations of students more carefully and detect more nuanced differences between groups. The inclusion of only four teachers also limits the generalizability of this pilot study; specifically, future research should focus on a larger sample of teachers to gauge the ability of diverse teachers to implement the strategies effectively. In addition, this sample of students is specific to its geographic location in southwest United States; future research should investigate the effectiveness of the language stimulation techniques used here for bilingual and low socioeconomic status students from more geographically diverse populations in the U.S. and abroad.

In addition, we must also consider that a relatively small intervention (2 days of professional development) over a relatively long intervention time (6 months) will likely also introduce various uncontrolled effects in the environment. Thus, the changes in the children's expressive and receptive language may be due to other factors, aside from the intervention with teachers.

Two days of professional development on language stimulation techniques may not have been an adequate amount of time to develop lasting change in the pedagogy of the early childhood teachers. Future studies should also consider the implementation of follow-up professional development experiences to reinforce learning across time.

Another limitation to the study is the lack of data regarding the comparison group. For example, it is unknown how much transfer of knowledge occurred between the intervention teachers and the comparison group teachers. As all four teachers in the study taught at the same childcare center, it is likely that they shared resources and information about the language stimulation techniques, even though they were instructed against the transfer of strategies and the control group promised training 
following the study. Future research coming from this pilot study should monitor and observe the language stimulation techniques used in both the intervention and comparison group classrooms.

\section{Implications}

Despite these limitations, the results of this study of simple integration of language techniques into daily classroom teaching do have implications, which upon further investigation may affect change for policy makers, administrators, and teachers in the field of early childhood education across national borders, with particular implications for childcare and educational policy. Where the National Early Literacy Panel (NELP 2008) noted children between 3 and 5 years of age did not obtain as large a language boost from interventions as did younger children under 3, the present study on 4-year-old Head Start high-need preschoolers suggests the present intervention may have merit in developing expressive language with this difficult-to-influence age level. Future research should expand the scope of the present study to include a larger range of ages and more geographically diverse settings plus consider alternate strategies for developing the more advanced receptive language levels which may not be particularly responsive to ILS techniques focused on lower language expressive development; such higher receptive language levels may indicate a readiness for fluency building following a 'language jumpstart' in expressive language skills.

Although the NELP (2008) reported limited studies on how to support young children learning English and stated there is still a lack of clarity on which developmental pathways to consider when teaching children whose first language is other than English (Abdullah-Welsh et al. 2009), the Spanish-speaking second language learners in the present study did make gains at a similar rate as their native English-speaking peers. Future research should examine this population more specifically, as well as consider how these intervention strategies might benefit older second language learners with low levels of English language development.

\section{Conclusions}

Overall, this research serves as a pilot study of the effectiveness of professional development regarding language stimulation techniques for Head Start teachers on the receptive and expressive English language development of their preschool children. The preliminary results indicate positive expressive language outcomes for children, and indicate the need for expanded studies to investigate the generalizability and replicability of these findings. In short, this research begins to indicate effectiveness of ILS techniques in early language development, which may have important implications for early childcare centers and educational policy on an international scope.

\section{Consent}

Informed consent was obtained for the publication of this report and any accompanying images. 


\section{Notes}

We would like to thank Dr. Dorothy Lee Gottshall for her valuable assistance with all of the testing and coding of data used in this study, and to Dr. Charles Frederick Abel and the editors of this journal for their editorial assistance.

This research was conducted with funds from the Margaret Hoover Perkins Research Professorship Award and the Early Childhood Research and Development Grant provided to the James I Perkins College of Education through the Stephen F. Austin State University Research Development Program. Conclusions expressed in this study are the researchers' alone.

\section{Appendix A}

Sample questions from multiple choice pre/post training test

\section{A child who says NO words}

He IS - holding a truck and spinning the wheels

Best response/teacher should say:

A__rooom vroom (show how to play w the truck)

B__spinning the wheels

C___ Truck. That's a truck. May I play with the truck, too?

D__ What are you doing with the truck?

$\mathrm{E} \_$Y You have a truck. Can you make it move?

\section{A child who speaks FEW words}

She SAYS - "Doll"

Then she puts the doll into the tub of water and washes it.

Best response/teacher should say:

A__ Is that your doll? Is your doll going to get a bath?

B__ Let's wash the baby doll. Where's the soap?

C___Yes, doll. You are washing the doll.

D__ Baby doll. Where are you? There you are! (playful)

$\mathrm{E} \_$The doll is getting a bath. Baby doll will be nice and clean.

\section{A child who speaks in PHRASES}

She SAYS - "He gots more."

Best response/teacher should say:

A__ SAY: He HAS more than I have.

B__ Are you sure? Let's count them and see.

$\mathrm{C} \_$He has more? He has more than you?

D__ Let's see, what we can do about that?

E__ That's not fair. Tell him how you feel.

A child who speaks in SENTENCES

A child sitting next to Paul says,

"I sad. I not get to play."

Best response/teacher should say:

A__ You are sad? Tell Paul you want to play.

B__ Let's talk to Paul. Tell him it's your turn.

C__ You did not get to play? What did Paul do to you?

D__ SAY: I'm sad. I did not get to play. (modeling)

E___ I'll play with you. What would you like to play? 


\section{Appendix B}

Classroom fidelity observation rubric

'Good Talking With You'

Language strategies implementation monitoring

Teacher observation evaluation

Teacher:

Date/Time:

Observer:

Number of Students:

Observation Number:

Typical behaviors noted (+ = often, $*$ some, $-=$ infrequently):

\begin{tabular}{|c|c|c|c|c|c|c|}
\hline 5 & 4 & 3 & 2 & 1 & 0 & score \\
\hline Excellent & Good & Average & Weak & Poor & $\begin{array}{l}\text { No } \\
\text { interaction } \\
\text { or other }\end{array}$ & \\
\hline $\begin{array}{l}\text { Looked for and } \\
\text { engaged in quality } \\
\text { interaction with most } \\
\text { children, most of the } \\
\text { time; few to no missed } \\
\text { opportunities }\end{array}$ & $\begin{array}{l}\text { Interaction } \\
\text { with many } \\
\text { children, } \\
\text { often; few } \\
\text { missed } \\
\text { opportunities }\end{array}$ & $\begin{array}{l}\text { Engagement } \\
\text { with children; } \\
\text { some missed } \\
\text { opportunities }\end{array}$ & $\begin{array}{l}\text { Engagement } \\
\text { with children; } \\
\text { too much } \\
\text { teacher talk; } \\
\text { too complex; } \\
\text { too many missed } \\
\text { opportunities }\end{array}$ & $\begin{array}{l}\text { Interaction and } \\
\text { support for most } \\
\text { children } \\
\text { was poor }\end{array}$ & & \\
\hline
\end{tabular}

Parallel Talk - short phrases - Say what the child is doing. (pushing the car)

Description - short phrase or sentence that describes. (The water is cold.)

Self Talk - describes what the teacher is doing. (I am painting.)

Expansion - restates. Child $=$ I got two foots. Adult $=$ You have two feet.

Expansion-Plus - adds more information. Child = truck. Adult = A big truck.

Invites others to talk, encourages children to talk to one another.

Seeks and capitalizes on opportunities.

Level is appropriate next step for particular child. (Not too high, not too low.)

Scoring rubric:

Competing interests

The authors declare that they have no competing interests.

\section{Authors' contributions}

CA and JN designed the study and analytic strategy. CA directed its implementation, including quality assurance and control. JN supervised the field activities and conducted the training. CA conducted the literature review. HW performed all statistical analyses and prepared the Methods and the Discussion sections of the text. CA, JN, and HW participated fully during the review and revisions process. All authors read and approved the final manuscript.

\section{Author details}

${ }^{1}$ Department of Elementary Education, Early Childhood Research Center, Stephen F. Austin State University, Station: 2428 Raguet Street, Box 13017-SFA, Nacogdoches, TX 75962, USA. ${ }^{2}$ Perkins College of Education, Stephen F. Austin State University, Station: 2428 Raguet Street, Box 13017-SFA, Nacogdoches, TX 75962, USA. ³ Department of Foundations and Secondary Education, College of Education and Human Services, University of North Florida, Building 57, room 2308; 1 UNF Drive, Jacksonville, FL 32224, USA. 


\section{References}

Abdullah-Welsh, N, Flaherty, J, \& Bosma, J. (2009). Technical report: Recommendations for future early childhood literacy research. Washington, DC: West Ed. Retrieved from http://lincs.ed.gov/publications/pdf/ ECL_Recommendation09.pdf.

Bohannon, J, \& Bonvillian, JD. (1997). Theoretical approaches to language acquisition. In JB Gleason (Ed.), The development of language (4th ed., pp. 259-316). Boston, MA: Allyn and Bacon.

Bouchard, C, Bigras, N, Cantin, G, Coutu, S, Blain-Brière, B, Eryasa, J, \& Brunson, L. (2010). Early childhood educators' use of language-support practices with 4-year-old children in childcare centers. Early Childhood Educ J, 37, 371-379.

Bredekamp, S. (2011). Vygotsky and sociocultural theory. In S Bredekamp (Ed.), Effective practices in early childhood education: Building a foundation (pp. 111-113). Upper Saddle River: NJ: Pearson Education.

Burger, K. (2010). How does early childhood care and education affect cognitive development? An international review of the effects of early interventions for children from different social backgrounds. Early Childhood Research Quarterly, 25, 140-165.

Cornerstones: An Early Literacy Series. (2009). National Institute for Literacy, National Institute of Child Health and Human Development, US Department of Education and U.S. Department of Health and Human Services. (2009). Learning to talk and listen: an oral language resource for early childhood caregivers (ED-04-CO-0041). RMC Research Corporation. Retrieved from https://lincs.ed.gov/publications/pdf/ECL_Recommendation09.pdf

Cuthrell, K, Stapleton, J, \& Ledford, C. (2010). Examining the culture of poverty: promising practices. Prev Sch Fail, 54, 104-110.

Diaz-Rico, L. (2013). Strategies for teaching English learners. Upper Saddle River, NJ: Pearson.

Dickinson, D. (2001). Large group and free-play times: Conversational settings supporting language and literacy development. In D Dickinson \& PO Tabors (Eds.), Beginning literacy with language (pp. 223-255). Baltimore, MD: Brookes.

Dunn, LM, \& Dunn, DM. (2007). Peabody picture vocabulary test manual (4th ed.). Minneapolis, MN: Pearson.

Educational Productions, Inc. (1987). Good talking with you language techniques through conversation: Video training series. Educational Productions. Portland, Oregon. http://trove.nla.gov.au/work/36575531?q\&versionld=47348486

Fernald, A, Marchman, VA, \& Weisleder, A. (2013). SES differences in language processing skill and vocabulary are evident at 18 months. Dev Sci, 16, 234-248. doi:10.1111/desc.12019.

Fry, R, \& Gonzales, F. (2008). One-in-five and growing fast: A profile of Hispanic public school students. Washington, DC: Pew Hispanic Center. Retrieved from http://www.pewhispanic.org/files/reports/92.pdf.

Glennen, S, Nippold, M, \& Larrivee, L. (2014). A longitudinal study of language and speech in children who were internationally adopted at different ages. Language, Speech \& Hearing Services In Schools, 45, 185-203.

Goodrich, J, Lonigan, CJ, \& Farver, JM. (2014). Children's expressive language skills and their impact on the relation between first- and second-language phonological awareness skills. Sci Stud Read, 18, 114-129. doi:10.1080/10888438.2013.819355

Hart, B, \& Risley, TR. (2003). The early catastrophe: the 30 million word gap by age 3. Am Educ, 27, 4-9.

Hoff, E. (2001). Language development (p. 12-25). Bellmont, CA: Wadsworth.

Hurley, S, \& Villamil, TJ. (2001). Literacy assessment of second language learners. Boston, MA: Allyn \& Bacon.

Jarvis, H., \& Krashen, S. (2014). Is CALL obsolete? Language acquisition and language learning revisited in a digital age. TESL-EJ Teaching English as a Second or Foreign Language. 17(4). Retrieved from http://www.tesl-ej.org/wordpress/ issues/volume17/ej68/ej68a1/.

Justice, LM, Mashburn, A, Pence, KL, \& Wiggins, A. (2008). Experimental evaluation of a preschool language curriculum: influence on children's expressive language skills. Journal of Speech, Language \& Hearing Research, 51, 983-1001.

Krashen, SD. (1982). Principles and practice in second language acquisition. Retrieved from http://www.sdkrashen.com/content/books/principles_and_practice.pdf

Law, J, McBean, K, \& Rush, R. (2011). Communication skills in a population of primary school-aged children raised in an area of pronounced social disadvantage. Int J Lang Commun Disord, 46, 657-664. doi:10.1111/j.14606984.2011.00036.x.

Lessow-Hurley, J. (2003). Meeting the needs of second language learners: An educator's guide. Alexandria, VA: Association for Supervision and Curriculum Development.

Levine, L, \& McCloskey, M. (2013). Language acquisition and language learning in the classroom. In Teaching English Language and Content in Mainstream Classes; One Class, Many Paths (pp. 18-39). Upper Saddle River, NJ: Pearson.

Lonigan, CJ, Farver, JM, Nakamoto, J, \& Eppe, S. (2013). Developmental trajectories of preschool early literacy skills: a comparison of language-minority and monolingual-English children. Dev Psychol, 49, 1943-1957. doi:10.1037/ a0031408

Lopez, MH, \& Velasco, G. (2011). The toll of the great recession; childhood poverty among Hispanics sets record, leads nation. Pew Research Center: Pew Hispanic Center. Retrieved from http://www.pewhispanic.org/files/2011/10/ 147.pdf.

McLeod, SA. (2007). Lev Vygotsky. Retrieved from http://www.simplypsychology.org/vygotsky.html\#ZPD.

National Association for the Education of Young Children (NAEYC). (2009). NAEYC standards for early childhood professional preparation programs: Position statement. Retrieved http://www.naeyc.org/files/naeyc/file/positions/ ProfPrepStandards09.pdf

National Clearinghouse for English Language Acquisition and Language Instruction Educational Programs (NCELA). (2011). Demographics: Who are young English learners? Retrieved from www.ncela.us/files/uploads/9/ EarlyChildhoodShortReport.pdf

National Institute for Literacy, \& National Center for Family Literacy (2008). Developing early literacy: Report of the National Early Literacy Panel (NELP) - A scientific synthesis of early literacy development and implications for interventions. (IAD-01-1701 and IAD-02-1790). Washington, DC:US Government Printing Office. Retrieved from http://lincs.ed.gov/ publications/pdf/NELPReport09.pdf.

National Institute of Child Health and Human Development. Report of the National Reading Panel (2000). Teaching children to read: An evidence-based assessment of the scientific research literature on reading and its implications for reading instruction (NIH Publication No. 00-4769). Washington, DC: U.S. Government Printing Office. 
Nelson, K, Welsh, J, Camarata, S, Butkovsky, L, \& Camarata, M. (1996). Effects of imitative and conversational recasting treatment on the acquisition of grammar in children with specific language impairment and younger language normal children. J Speech Hear Res, 39, 850-859.

Owens, R. (2008a). Sociolinguistic theory. In language development: An introduction. Boston, MA: Pearson.

Owens, R. (2008b). Language-learning and teaching processes and young children. In RE Owens (Ed.), Language Development (7th Ed., p. 185). Columbus, OH: Allyn \& Bacon.

Pence, KL, \& Justice, LM. (2008). Language development from theory to practice. New Jersey: Pearson.

Peterson, C, Mayer, L, Summers, JA, \& Luze, G. (2010). Meeting needs of young children at risk for or having a disability. Early Childhood Education Journal, 37, 509-517.

Pikulski, J, \& Tobin, A. (1989). Factors associated with long-term reading achievement of early readers. In J SMcCormick, ZP Scharer, \& P O'Keefe (Eds.), Cognitive and social perspectives for literacy research and instruction. Chicago, IL: National Reading Conference.

Rafferty, Y, \& Griffin, K. (2010). Parenting behaviours among low-income mothers of preschool age children in the USA: implications for parenting programmes. International Journal of Early Years Education, 18, 143-157.

Schmid, MS, \& Kopke, B. (2007). Bilingualism and attrition. In B Kopke, MS Schmid, M Keijzer, \& S Dostert (Eds.), Language attrition: Theoretical perspectives (p. 1-7). Amsterdam, Philadelphia: John Benjamins.

Tabors, PO. (1998). What early childhood educators need to know: developing effective programs for linguistically and culturally diverse children and families. Young Children, 53, 24-31.

Taffe, SW. (2009). Vocabulary instruction for diverse students. In L Morrow, R Reuda, \& D Lapp (Eds.), Handbook of research on literacy and diversity (pp. 320-336). New York, NY: Guildford Press.

Tinajero, J, Villamil, P, Hurley, S, Lozano, E, \& Varela, P. (1998). Developing language and literacy in bilingual classrooms. In L Gonzalez, A Huerta-Macias, \& J Tinajero (Eds.), Educating Latino students: A guide to successful practice (p.143-160). Lancaster, PA: Technomic.

Tsybina, I, Girolametto, L, Weitzman, E, \& Greenberg, J. (2006). Recasts used with preschoolers learning English as their second language. Early Childhood Education Journal, 34, 177-185.

US Census Bureau. (2010). State and county quick facts. Retrieved from http://quickfacts.census.gov/qfd/states/48000.html

Vygotsky, L. (1933). Play and its role in the mental development of the child. Retrieved from https://www.marxists.org/ archive/vygotsky/works/1933/play.htm.

Warren, SF, \& Yoder, PJ. (1994). Communication and language intervention: why a constructivist approach is insufficient. Journal of Special Education, 28, 248-258.

Westby, C, \& Hwa-Froelich, DA. (2010). Difficulty, delay, or disorder: What makes English hard for English language Learners? In M Shatz \& LC Wilkinson (Eds.), The Education of English Language Learners: Research to Practice (p. 216). New York: NY: Gilford.

Whitted, K. (2010). Understanding how social and emotional skill deficits contribute to school failure. Prev Sch Fail, 55, 10-16. Williams, KT. (2007). Expressive vocabulary test manual (2nd ed.). Minneapolis, MN: Pearson.

\section{Submit your manuscript to a SpringerOpen ${ }^{\circ}$ journal and benefit from:}

- Convenient online submission

- Rigorous peer review

- Immediate publication on acceptance

- Open access: articles freely available online

- High visibility within the field

- Retaining the copyright to your article 